\title{
Self-perceived social status: its relation to aggression and personality traits in two Spanish speaking samples
}

\author{
Estatus social auto-percibido: su relación con la agresión y \\ rasgos de personalidad en dos muestras hispano-hablantes
}

\author{
David Monge-López ${ }^{1}$ \\ Universidad Hispanoamericana, Costa Rica
}

\author{
Sara Álvarez-Solas ${ }^{2}$ \\ Universidad Regional Amazónica Ikiam, Ecuador
}

\begin{abstract}
Dominance and prestige are two strategies to achieve status in humans. Dominance is the use of threat and aggression, and prestige is the pursuit of cultural achievement. This research presents a study carried out through selfreport measures with two native Spanish speaking samples from Madrid (Spain) and San José (Costa Rica). Self-perceived dominance and prestige were correlated with dimensions of aggression and the big five personality traits. Results showed that a component that grouped different aggression subscales and agreeableness was the best predictor of dominance in samples of men and women of both countries. Prestige was mainly predicted by conscientiousness and extraversion in both samples and by low hostility and neuroticism but only in Spanish men.

Keywords. Social status, prestige, dominance, personality.

Resumen. Dominancia y prestigio se han propuesto como estrategias para alcanzar estatus en humanos. La dominancia es el uso de amenazas y agresión, y el prestigio es la búsqueda de logros culturales. Esta investigación fue llevada a cabo utilizando cuestionarios en muestras de habla hispana: Madrid (España) y San José (Costa Rica). La dominancia y el prestigio auto-percibidos fueron correlacionados con dimensiones de la agresión y los cinco grandes rasgos de personalidad. Un componente que agrupó las subescalas de agresión y la afabilidad fue el mejor predictor de la dominancia en ambos sexos de ambos países. El prestigio fue predicho por la escrupulosidad y la extroversión en sendas muestras y por bajas puntuaciones en hostilidad y neuroticismo en hombres españoles.
\end{abstract}

Palabras clave. Estatus social, prestigio, dominancia, personalidad.

\footnotetext{
${ }^{1}$ David Monge-López. Universidad Hispanoamericana, UNED, Costa Rica. Dirección postal: Barrio Aranjuez, San José, Costa Rica. E-mail: davidml79@gmail.com

${ }^{2}$ Sara Álvarez-Solas. Universidad Regional Amazónica IKIAM, Tena, Ecuador. E-mail: sarahez61@hotmail.com
} 


\section{Introduction}

Henrich and Gil-White (2001) developed a framework about human social status; their perspective proposed two means of reaching social positions: dominance and prestige. While dominance is based on the use of aggression and intimidation to induce fear, prestige is a product of the improvement of the quality of information that has been obtained by cultural learning (see Krützen et al., 2005; Taylor \& Toth, 2011; van Schaik \& Burkart, 2011 about the concept of cultural learning or cultural transmission). Prestige is based on the display of skills and knowledge in different behavioral domains, such strategy leads to the admiration and respect from others' point of view. This perspective can be termed as "dual strategy theory" (DST).

DST has motivated different projects that have made progress toward the understanding of the characteristics of both forms of human status. Research has been carried out in fields like personality psychology (Buttermore \& Kirkpatrick, 2009), physiological psychology (Johnson, Burk \& Kikpatrick, 2007), mate choice (Snyder, Kirkpatrick \& Barret, 2008), the psychology of emotions (Cheng, Tracy \& Henrich, 2010), group behavior (Cheng, Tracy, Foulsham, Kingstone \& Henrich, 2013; Cheng \& Tracy, 2013; 2014) and the study of social dilemmas in intergroup situations (Halevy, Chou, Cohen \& Livingston, 2012).

Dominance and prestige have also been studied in indigenous groups and have been related to different social consequences and biological fitness indicators, for example both dominance and prestige have been related too higher nutritional status (von Rueden, Gurven \& Kaplan, 2011). In addition, both strategies have been also related to higher marital fertility, lower offspring mortality, and support from allies in conflicts (von Rueden, Gurven \& Kaplan, 2008) and prestige has been related additionally to community influence and respect in a group while dominance has been related to fighting ability and physical size (Reyes-García et al., 2009).
Additionally, in developmental psychology an independent line of research has reported similar strategies in behavioral patterns during infancy and adolescence. Research has shown that children and teenagers behave using intimidation and aggression to others or using prosociality and trying to influence peers, while children use aggressive behavior in early elementary school years; later, such tendencies disappear and prosocial strategies are more important in high school (Hawley, 2002; Hawley, Little \& Pasupathi, 2002; Hawley, Little \& Card, 2008).

Along with the research just described, studies have also shown that social status is a phenomenon that links social behavior with biological and developmental processes. Some authors have argued that cultural prestige could be considered the most important pathway to reaching status in modern environments; further, prestige could be considered the only certainly relevant in contemporary societies (Barkow, 1975; Chapais, 2015). From this perspective, dominance would be used only for those who have had socialization experiences that keep such type of strategy active but it would be a less valuable tendency in adults (Barkow, 1975), or it would be a behavioral tendency mainly present in the early development (Hawley, 2002; Hawley, Little \& Card, 2008; Hawley, 2014).

Following the proposal of Henrich \& Gil-White (2001), dominance has been characterized as a strategy based on the use of aggression, coercion and intimidation. On the other hand, prestige has been described as a strategy based on the display of skills and knowledge. It could be expected that the self-report of different dimensions of aggressive behavior would correlate positively with dominance but not with prestige.

Following the proposal of Buss \& Perry (1992), we consider four dimensions of self-report aggressive behavior: a) physical aggression: direct contact to other persons in order to harm them, b) verbal aggression: direct contact to other persons using language in order to offend them, c) anger: 
physiological and emotional activation related to aggression, and d) hostility: feeling of opposition representing the cognitive component of aggression. We expect that all four dimensions of aggression will be positively related to dominance because only this status-seeking strategy uses aggression to reach social positions.

As in the case of aggressive behavior, personality traits could correlate with self-perceived status strategies. The display of different strategies to seek social status could be related to specific psychological profiles that assist behavior in the objective to reach high positions in social groups; the recognition of these profiles could help in order to identify the traits that help in particular pathways of status-seeking processes.

Taking into account the five-factor model of personality (Costa \& McCrae, 1992) and based on previous research and theoretical arguments, it is possible to predict how every personality trait could correlate to dominance and prestige. As it is widely known, the five factor model is composed of five dimensions, a) openness to experience: tendency to have imagination, preference for variety, curiosity and aesthetic sensitivity; b) conscientiousness: worrying about take obligations seriously, to be organized, systematic and self-disciplined; c) extraversion: tendency to be outgoing, talkative, socially oriented and behaviorally energetic; d) agreeableness: to be kind, sympathetic, warm and cooperative in social relations; and e) neuroticism: tendency to experience negative emotions as anxiety, anger, envy, frustration, sad mood or loneliness

Previous research suggests that openness to experience and conscientiousness are positively related to self-perceived prestige, these two personality traits can assist the gathering of valuable cultural information (Buttermore \& Kirkpatrick, 2009; Cheng, Tracy \& Henrich, 2010). We do not expect any association of these two traits with dominance.
Past works have also reported a positive association of extraversion with social status (Anderson et al., 2001); this seems to be the case for both, dominance and prestige (Buttermore \& Kirkpatrick, 2009). Based on these findings we expect a positive correlation of self-perceived status strategies with extraversion.

While it is expected that both dominance and prestige are positively related to extraversion, a different relationship is expected between status strategies and agreeableness. This trait has been defined as a tendency to be kind, generous, sympathetic and warm with others (Costa \& McCrae, 1991; Thompson, 2008). This description seems clearly incompatible with dominance, but it could be a desirable trait that would enhance a strategy based on cultural prestige. Thus, we expect a negative correlation between self-perceived dominance and agreeableness but a positive association of this personality trait with self-perceived prestige.

Finally, the possible relation of self-perceived status strategies with neuroticism deserves detailed consideration. A previous study has reported that people who seek prestige are usually viewed as likable, but those who adopt a dominance strategy are not liked by their peers (Cheng, et al, 2013). In addition, Buttermore \& Kirkpatrick (2009) found a negative relation between neuroticism and self-perceived prestige and a positive one between emotional stability and self-perceived prestige. This evidence suggests that neuroticism presents an inverse correlation with self-perceived prestige. Possibly, low levels of selfperceived prestige lead to the experience of negative emotionality and ceteris paribus the two traits are negatively related.

Additionally, when considering the association of neuroticism and self-perceived dominance, there are two possibilities. The first one follows an argument presented in Buttermore and Kirkpatrick (2009); these authors proposed a negative association between neuroticism and self-perceived dominance because self-perception of social status of any type would protect against neurotic experiences. An alternative possibility is that there will be a positive relation between self-perceived dominance and neuroticism 
because dominance is a trait that is rejected by others and this rejection could lead to the experience of negative emotionality (Cheng, et al. 2013).

Relatively few empirical studies show advancements regarding how different psychological traits are related to status strategies in different cultural contexts. To date, there are no studies that explore the hypotheses exposed in the previous paragraphs in Spanish-speaking countries. The purpose of the present study was to analyze the association between two self-perceived social status strategies, prestige and dominance, with different dimensions of aggression and the big five personality traits. In short, our study was guided by the following hypotheses:

Hypothesis 1: There will be positive associations between self-perceived dominance and different dimensions of aggression, but different expressions of aggression will not be related with self-perceived prestige.

Hypothesis 2: There will be positive associations of openness to experience and conscientiousness with self-perceived prestige, but these personality traits will not be related with self-perceived dominance.

Hypothesis 3: There will be a positive correlation of extraversion both with self-perceived dominance and prestige.

Hypothesis 4: There will be a negative association between agreeableness and self-perceived dominance, but a positive one with self-perceived prestige.

Hypothesis 5: There will be a negative correlation between neuroticism and self-perceived prestige. Moreover, there are two perspectives while considering the relation between neuroticism and self-perceived dominance: one predicts a negative association between these variables; the other predicts a positive one.

Additionally, we do not expect differences either by sex or by country in the associations that were predicted.

\section{Method}

The current study was correlational, developed with two Spanish speaking samples from two different countries.

\section{Participants}

Two samples of university students and graduates were studied. One of the samples was from Madrid, Spain $(n=234), 112$ participants $(47.86 \%)$ of the sample were men. Their mean age was 23 years and 11 months with a standard deviation of 33.54 months. In terms of nationality, 96.6\% were Spanish and 3.4\% were from other nationalities.

The other sample was from San José, Costa Rica ( $n$ =216), 110 participants $(50.93 \%)$ were men. Their age had a mean of 23 years and 8 months, and a standard deviation of 34.44 months. Participants were from Costa Rica in $98.5 \%$ of the cases.

\section{Measures}

The study used the following measures.

-Self-perceived social status scale (SSSS). The Spanish version (Monge-López \& Escorial, 2015) of this scale originally developed by Buttermore (2006), is composed of 11 items (5 evaluate dominance and 6 evaluate prestige). It excludes reverse coded items presented in the original; previous work showed that they present low correlations with their subscales. The subscales presented adequate reliability both in Spain (dominance $\alpha=.82$ and prestige $\alpha=.78$ ) and in Costa Rica (dominance $\alpha=.80$ and prestige $\alpha=.71$ ).

-Aggression questionnaire. The Spanish version (Andreu, Peña \& Graña, 2002) of this measure originally developed by Buss and Perry (1992), is composed of 29 items and includes 4 subscales: physical aggression, verbal aggression, anger and hostility. With the exception of verbal aggression subscales, it presented good reliability in Spain (physical aggression $\alpha=.83$, verbal aggression $\alpha=$ .63 , anger $\alpha=.74$ and hostility $\alpha=.74$ ), and in Costa Rica all subscales presented good reliability (physical aggression $\alpha=.75$, verbal aggression $\alpha=$ .70 , anger $\alpha=.73$ and hostility $\alpha=.74$ ).

-NEO-FFI. A Spanish version (Cordero, Pamos \& Seisdedos, 1999) of this measure of the five-factor model of personality (Costa \& McCrae, 1992) is composed of 60 items, and it includes 5 subscales: 
openness to experience, conscientiousness, extraversion, agreeableness and neuroticism. Reliabilities of the subscales were good both in Spain (openness $\alpha=$ .81; conscientiousness $\alpha=.86$; extraversion $\alpha=.80$, agreeableness $\alpha=.76$ and neuroticism $\alpha=.87$ ) and in Costa Rica (openness $\alpha=.75$; conscientiousness $\alpha$ $=.85$; extraversion $\alpha=.79$, agreeableness $\alpha=.73$ and neuroticism $\alpha=.85$ ).

\section{Procedure}

A website was designed to include the different questionnaires of the study. Participants could read the objective of the research and ethical statements before beginning to complete the measures. To collect data, professors and students distributed the website link in class and other contexts; the participants completed the measures at the time and place they preferred. Participants were not reimbursed in any way. Data were gathered in a MySQL database and exported to Excel to prepare for the analysis.

\section{Data analysis}

The mean, standard deviation and coefficient of variation were obtained for measures of dominance and prestige. In addition, the correlation between two self-reported status strategies was obtained. We also tested the reliability of all subscales using Cronbach's alpha coefficient. In cases of an alpha coefficient below 0.7 , the subscale was maintained for analysis but the following correlations were corrected for attenuation (Sijtsma, 2009).

Pearson correlations were obtained to test the hypothesis. Those variables that presented at least a moderate zero order correlation (above .3) with dominance or prestige, were selected for regression analysis. In order to avoid collinearity problems between predictors, a principal component analysis was performed (PCA) and selected every component as a predictor in the regression model (Liu, Kuang, Gong \& Hou, 2003).
The PCA used a Varimax rotation and conserved components whose eigenvalues were greater than 1. Correlational and regression analyses were performed for every subsample according sex and country; regression used a robust standard error procedure. Procedures were executed using R-Commander (Arriaza et al, 2008; Crawley, 2005).

\section{Ethical statement}

As described previously, the website included a first page in which the participants were informed about the research objectives and confidentiality. Voluntary participation was assured. Formal procedures for the approval of the study were followed in the university where it was developed.

\section{Results}

Table 1 includes means and standard deviations of all variables.

Table 2 presents the results of correlations of the dominance and prestige subscales with different variables. A significant correlation between dominance and prestige was obtained in Spain, but it was of low magnitude $(r=.18, p=.01)$. In Costa Rica, dominance and prestige did not present a significant correlation $(r$ $=.08, n . s . p=.228$ ).

When considering the results presented in Table 2 and following the hypotheses proposed, all the predictions were partially supported, in most cases there is evidence of the expected relations in some subsamples but not in others. The only prediction that was supported in men and women from both countries was the negative correlation between neuroticism and self-perceived prestige (see "Discussion" section for a complete consideration of these results).

When considering every subsample according to sex and country that presented more than one predictor variable that correlated above .3 with the criterion variable, effectively, there was collinearity in all cases and PCA extracted only one component in all cases too. That was the case for self-perceived dominance (eigenvalue $=2.49)$ and self-perceived prestige (eigenvalue $=2.57$ ) in men from Spain and for self-perceived dominance 
Table 1

Means and Standard Deviations of All Measures

\begin{tabular}{lcccc}
\hline & \multicolumn{2}{c}{ Means } & \multicolumn{2}{c}{ Standard deviations } \\
& Spain & Costa Rica & Spain & Costa Rica \\
\hline Self-perceived dominance & 16.08 & 17.66 & 5.82 & 6.41 \\
Self-perceived prestige & 30.7 & 32.44 & 4.62 & 4.79 \\
Physical aggression & 10.74 & 11.79 & 7.13 & 6.35 \\
Verbal aggression & 7.29 & 8.15 & 3.77 & 4.58 \\
Anger & 11.53 & 12.03 & 5.14 & 5.48 \\
Hostility & 14.15 & 14.73 & 5.52 & 5.84 \\
Openness to experience & 44.25 & 43.11 & 7.55 & 6.80 \\
Conscientiousness & 42.41 & 43.95 & 8.03 & 7.71 \\
Extroversion & 40.42 & 40.58 & 7.02 & 7.95 \\
Agreeableness & 44.73 & 42.76 & 6.44 & 6.83 \\
Neuroticism & 35.22 & 34.94 & 9.14 & 8.68 \\
\hline
\end{tabular}

Table 2

Pearson Zero Order Correlations for Dominance and Prestige with Different Variables According Sex and Country

\begin{tabular}{|c|c|c|c|c|c|c|c|c|}
\hline & \multicolumn{4}{|c|}{ Madrid, Spain } & \multicolumn{4}{|c|}{ San José, Costa Rica } \\
\hline & \multicolumn{2}{|c|}{ Dominance } & \multicolumn{2}{|c|}{ Prestige } & \multicolumn{2}{|c|}{ Dominance } & \multicolumn{2}{|c|}{ Prestige } \\
\hline & $\mathrm{M}$ & $\mathrm{W}$ & $\mathrm{M}$ & $\mathrm{W}$ & $\mathrm{M}$ & $\mathrm{W}$ & $\mathrm{M}$ & $\mathrm{W}$ \\
\hline Physical aggression & $.31^{* *}$ & $.21 *$ & .05 & -.07 & $.35^{* * *}$ & $.26^{* *}$ & -.03 & .06 \\
\hline \multirow[t]{2}{*}{ Verbal aggression } & $.30 * *$ & $.26^{* *}$ & -.13 & -.004 & $.50^{* * *}$ & $.43^{* * *}$ & .14 & .17 \\
\hline & $\left(.42^{* * *}\right)$ & $\left(.36^{* *}\right)$ & $(-.18)$ & $(-.006)$ & & & & \\
\hline Anger & $.30^{* *}$ & $.35^{* * *}$ & -.13 & -.02 & $.41^{* * *}$ & $.29 * *$ & -.13 & .01 \\
\hline Hostility & $.32^{* *}$ & .14 & $-.32^{* *}$ & $-.18^{*}$ & $.21 *$ & $.20^{*}$ & -.16 & -.17 \\
\hline Openness & .07 & .08 & $.25^{* *}$ & .08 & .04 & .10 & $.26 * *$ & .17 \\
\hline Conscient & -.11 & -.01 & $.41^{* *}$ & $.31^{* * *}$ & -.17 & $-.19 *$ & $.30^{* *}$ & .18 \\
\hline Extraversion & -.01 & .13 & $.37^{* *}$ & .18 & .09 & -.06 & $.37 * * *$ & .13 \\
\hline Agreeableness & $-.65^{* * *}$ & $-.42^{* * *}$ & -.06 & .03 & $-.62^{* * *}$ & $-.58^{* * *}$ & .11 & .01 \\
\hline Neurosis & $.27^{* *}$ & -.04 & $-.46^{* *}$ & $-.27 * *$ & .09 & .11 & $-.23 *$ & $-.21 *$ \\
\hline
\end{tabular}

Note. M: Men. W: Women. ${ }^{*} p=.05,{ }^{* *} p=.01,{ }^{* *} p=.001$ Correlations corrected for attenuation for verbal aggression are presented in parenthesis. Numbers in bold represent those correlations that were at least of a moderate magnitude. 
Table 3

Principal Component Regression Predicting Dominance and Prestige in Different Subsamples

\begin{tabular}{|c|c|c|c|c|}
\hline Criterion & Predictor & Proportion of variance* & $\beta^{* *}$ & $\mathrm{R}^{2}, \mathrm{~F}(d f) * *$ \\
\hline $\begin{array}{l}\text { Dominance Men } \\
\text { Spain }\end{array}$ & (All Aggression,-Agreeable.) & .49 & .54 & $\begin{array}{c}\mathrm{R}^{2}=.293 \\
\mathrm{~F}(1,110)=45.49\end{array}$ \\
\hline $\begin{array}{l}\text { Dominance Women } \\
\text { Spain }\end{array}$ & $\begin{array}{c}\text { (-Anger, -Verb. Aggr. } \\
\text { Agreeable.) }\end{array}$ & .59 & -.44 & $\begin{array}{c}\mathrm{R}^{2}=.198 \\
\mathrm{~F}(1,120)=29.54\end{array}$ \\
\hline $\begin{array}{l}\text { Prestige Men } \\
\text { Spain }\end{array}$ & $\begin{array}{c}\text { (Hostil. Neurot.- } \\
\text { Conscien., -Extrav.) }\end{array}$ & .64 & -.48 & $\begin{array}{c}\mathrm{R}^{2}=.233 \\
\mathrm{~F}(1,110)=33.49\end{array}$ \\
\hline $\begin{array}{l}\text { Prestige Women } \\
\text { Spain }\end{array}$ & Conscientiousness*** & $.10^{+}$ & .31 & $\begin{array}{c}\mathrm{R}^{2}=.098 \\
\mathrm{~F}(1,120)=13.11\end{array}$ \\
\hline $\begin{array}{l}\text { Dominance Men } \\
\text { Costa Rica }\end{array}$ & $\begin{array}{c}\text { (Phys.agg, Verb. agg, } \\
\text { Ang., -Agreeable.) }\end{array}$ & .63 & -.59 & $\begin{array}{c}\mathrm{R}^{2}=.351 \\
\mathrm{~F}(1,108)=58.33\end{array}$ \\
\hline $\begin{array}{l}\text { Dominance Women } \\
\text { Costa Rica }\end{array}$ & (-Verb. aggr., Agreeable.) & .73 & .59 & $\begin{array}{c}\mathrm{R}^{2}=.343 \\
\mathrm{~F}(1,104)=54.42\end{array}$ \\
\hline $\begin{array}{l}\text { Prestige Men } \\
\text { Costa Rica }\end{array}$ & (Conscient., Extravers.) & .69 & .41 & $\begin{array}{c}\mathrm{R}^{2}=.167 \\
\mathrm{~F}(1,108)=21.63\end{array}$ \\
\hline $\begin{array}{l}\text { Prestige Women } \\
\text { Costa Rica }\end{array}$ & \multicolumn{4}{|c|}{ Non variable correlates above .3} \\
\hline
\end{tabular}

Note. Predictor represents the component identified in a PCA for every subsample. In all cases PCA extracted only one component. A negative sign indicates a variable that had a negative loading in the component.*Proportion of variance explained by the component. **All beta coefficients and $\mathrm{F}$ values were significant, $\mathrm{p}=.001$. ***PCA was not executed because only this variable correlates above .3 with the criterion variable. ${ }^{+} \mathrm{r}^{2}$ value related to the variable that correlates above .3 with the criterion variable.

in women from Spain (eigenvalue $=1.78$ ). Same situation occurred in Costa Rica when considering self-perceived dominance (eigenvalue $=2.51$ ) and self-perceived prestige (eigenvalue $=1.39$ ) in men and self-perceived dominance in women (eigenvalue = 1.46). All eigenvalues reported correspond to the only component extracted.

Table 3 presents the results of the principal component regression analysis for every subsample considering sex and country of the participants.

All predictors in all cases maintain a significant relation with the criterion variable; in all cases, the predictor was the component extracted in the PCA. Only when self-perceived prestige was the criterion variable in women from Spain the analysis had just one variable as a predictor and PCA was not executed. In this case, the relation between the predictor and the criterion was still significant. In the case of selfperceived prestige in women from Costa Rica, there were no predictors because no variable correlated above 0.3 and regression analysis was not executed.

\section{Discussion}

The present study established the associations between self-perceived status strategies and some psychological traits, dimensions of self-reported aggression as developed by Buss \& Perry (1992) and dimensions of personality traits as presented in the big five model (Costa \& McCrae, 1992). The first hypothesis proposed that all dimensions of aggression would correlate positively with dominance in all subsamples, but different expressions of aggression would not correlate with prestige. Results showed that almost all dimensions of aggression were positively related with dominance in all cases, and there were 
no associations between prestige and dimensions of aggression as well.

The only unexpected correlation was the negative association between prestige and hostility that was obtained in men and women from Spain. This result was especially important in the case of men when compared to other subsamples. Furthermore, it seems dependent on the context where data were collected because there was no association between these variables in Costa Rica. The result could be also related with the fact commented ahead, the negative relation between selfperceived prestige and neuroticism. Hostility could be a part of such trait too; in some cases, hostility could appear as a manifestation of a neurotic reaction when self-perceived prestige is diminished.

The second hypothesis predicted positive associations of openness and conscientiousness with self-perceived prestige. This hypothesis was supported in the samples of men of both countries; but in women from Spain there was only a positive relation between conscientiousness and prestige and women from Costa Rica did not present any association between these variables. These results suggest that the relations depending on sex and the cultural context where the study was carried out. The relation proposed by the hypothesis was mainly present in men, maybe men would obtain most social benefits and positive consequences from the expression of openness and conscientiousness and this lead to an improvement of their own cultural prestige.

The third hypothesis proposed a positive correlation with extraversion both with dominance and prestige. These predictions were not supported; only a positive relation between extraversion and prestige in men of both countries existed. As in the case of openness and conscientiousness in Costa Rica, it seems that this association depends on the sex of the participants, and it is not the generalized phenomenon that was expected. As in the previous result too, it seems that men are the ones that can obtain positive consequences from the expression of social valuable personality traits and this enhances their self-image of prestige.
The next hypothesis predicted a negative association between agreeableness and self-perceived dominance, and a positive relation between such personality trait and self-perceived prestige. The negative relation between agreeableness and dominance was in fact obtained. In all subsamples of both sexes and countries, it was one of the most generalized correlations obtained between a personality trait and one of the self-perceived status strategies.

On the other hand, the idea that agreeableness would correlate with prestige was not supported in any case; curiously in this case the positive relation between the valuable personality trait (agreeableness) and self-perceived prestige was not obtained. This study found no evidence that the phenomenon that occurred with openness, conscientiousness and extraversion could occur with agreeableness. Future studies could try to reply to these results and try to explain why it happened.

The last hypothesis proposed an inverse relation between neuroticism and self-perceived prestige; this prediction was completely supported in all subsamples of both sexes and countries; along with the negative association between dominance and agreeableness was the most supported prediction.

Last hypothesis also proposed two possible perspectives about the relation between neuroticism and self-perceived dominance; one predicts a negative correlation between these variables and the other predicts a positive one. Results showed only one positive relation between neuroticism and dominance in men from Spain; however, the magnitude of this association was low. None of the perspectives proposed received strong and consistent support; it seems that dominance is not consistently related with neuroticism at all.

Correlations obtained were of low and moderate magnitude in the majority of cases, only in the case of the inverse associations between dominance and agreeableness in men from both countries strong relations were obtained. In this type of studies moderate associations are usually the norm; it is quite 
rare to obtain strong associations (above 0.6) and they usually represent variables that are the same construct (Lodico, Spaulding \& Voegtle, 2006).

Regression analyses showed that only one component was enough to establish a predictor in all cases. In the case of dominance and in male samples, such predictor includes all aggression dimensions with the exception of hostility in Costa Rica, as well as a negative relation with agreeableness. In women, the component that served as a predictor also includes a negative relation with agreeableness, but it only includes anger and verbal aggression in Spanish women and verbal aggression in Costa Rican women. This result can be interpreted as evidence of sex differences in aggression as predictors of dominance. Such differences have been previously reported in research, typically direct forms of aggression (physical aggression) are used mainly by men, and there are fewer differences or no differences at all in dimensions like verbal aggression or anger (see Archer, 2004).

When considering prestige, conscientiousness was a predictor in men from both countries and in women from Spain. In male samples of both countries, extraversion joined conscientiousness as a personality trait that predicted the self-perception of prestige. In Spanish men, such positive personality traits seem to inhibit neuroticism and hostility and show how in some contexts self-perceived prestige helps the psychological health of the individual.

Taking into account other results, descriptive characteristics of the SSSS' subscales have shown that prestige always presents a higher mean and a lower standard deviation when compared to dominance; these characteristics seem to be generalized according to previous studies in other cultural contexts (Buttermore \& Kirkpatrick, 2009; Johnson, Burk \& Kirkpatrick, 2007).

People tend to be biased toward a high selfperception of prestige while the self-perception of dominance is a more variable phenomenon. Sustaining a bias of high self-perceived prestige could be related to the fact that this status seeking strategy has very positive social consequences. For example, Cheng, et al (2013) found that people that were considered prestigious were evaluated as agreeable people, this did not occur with people that were considered dominant. Cheng, Tracy \& Henrich (2010) related cultural prestige with authentic pride, a self-conscious emotion associated with self-confidence, agreeableness, work capability, energy, kindness and self-esteem (Hart \& Matsuba, 2007; Tracy, Cheng, Robins \& Trzesniewski, 2009; Tracy \& Robins, 2007). Our results seem to support this tendency, where both samples from Spain and Costa Rica showed high self-perception of prestige, possibly to obtain such direct benefits.

An important feature of these studies is that they have been developed with self-perception measures. This implies that we do not have information about whether aggression and personality traits are related with dominance and prestige when such variables are evaluated by different means such as ratings from other's point of view or observational methods. Future studies must consider alternative ways to measure these variables and asses the correlations between them. Achieving social status is an important motivation in human behavior. Positive outcomes related to possessing a favorable social position have probably sustained these behaviors in the evolutionary past and in present environments. Understanding both strategies of obtaining status and the consequences of acquiring and failing to sustain social positions may help to improve our knowledge related to the regulation of social behavior.

\section{References}

Anderson, C., John, O. P., Keltner, D. \& Kring, A. M. (2001). Who attains social status? Effects of personality and social attractiveness in social groups. Journal of Personality and Social Psychology, 81, 116-132. doi: 10.1037/0022-3514.81.1.116

Andreu, J. M., Peña, M. E., \& Graña, J. L. (2002). Adaptación psicométrica de la versión española del cuestionario de agresión. Psicothema, 14, 476-482.

Archer, J. (2004). Sex differences in aggression in real world settings: a meta-analytic review. Review of 
General Psychology, 8, 291-322. doi: 10.1037/10892680.8.4.291

Arriaza, A. J., Fernández, F., López, M. A., Muñoz, M., Pérez, S., \& Sánchez, A. (2008). Estadística básica con R y R-Commander. Cádiz, España: Universidad de Cádiz.

Barkow, J. (1975). Prestige and culture: a biosocial interpretation. Current Anthropology, 16, 553-572. doi: 10.1086/201619

Buss, A., \& Perry, M. (1992). The aggression questionnaire. Journal of Personality and SocialPsychology, 63, 452-459. doi: 10.1037/0022-3514.63.3.452

Buttermore, N. (2006). Distinguishing Dominance and Prestige: Validation of a self-report scale. Poster presented at the annual meeting of the Human Behavior and Evolution Society, Philadelphia, PA.

Buttermore, N., \& Kirkpatrick, L. (2009). Distinguishing Prestige and Dominance: Two Distinct Pathways to Status. Unpublished research project. University of Michigan.

Chapais, B. (2015). Competence and the evolutionary origins of status and power in humans. Human Nature, 26, 9227. doi: 10.1007/s12110-015-9227-6

Cheng, J. T., \& Tracy, J. L. (2013). The impact of wealth on prestige and dominance rank relationships. Psychological Inquiry, 24, 102-108. doi: 10.1080/1047840X.2013.792576

Cheng, J. T., \& Tracy, J. L. (2014). Toward a unified science of hierarchy: dominance and prestige are two fundamental pathways to human social rank. In J. T. Cheng, J. L. Tracy \& C. Anderson (Eds.). The Psychology of Social Status (pp. 3-28) New York: Springer. doi: 10.1007/978-1-4939-0867-7

Cheng, J. T., Tracy, J. L., Foulsham, T., Kingstone, A., \& Henrich, J. (2013). Two ways to the top: evidence that dominance and prestige are distinct yet viable avenues to social rank and influence. Journal of Personality and Social Psychology, 104, 103-125. doi: $10.1037 / \mathrm{a} 0030398$

Cheng, J, Tracy, J., \& Henrich, J. (2010). Pride, personality and the evolutionary foundations of human social status. Evolution \& Human Behavior, 31, 334-347. doi: 10.1016/j.evolhumbehav.2010.02.004

Cordero, A., Pamos, A., \& Seisdedos, N. (1999). Inventario de personalidad NEO Revisado (NEO PI-R) e Inventario NEO Reducido de cinco factores (NEO-FFI). Adaptación española. Madrid, España: TEA.

Costa, P. T., \& McCrae, R. R. (1991). Facet scales for agreeableness and conscientiousness: a revisión of the NEO personality inventory. Personality and Individual Differences, 12, 888. doi: 10.1016/01918869(91)90177-D

Costa, P. T. Jr., \& McCrae, R. R. (1992). Revised NEO Personality Inventory (NEO-PI-R) and NEO FiveFactor Inventory (NEO-FFI) manual. Odessa, FL: Psychological Assessment Resources.

Crawley, M. J. (2005). Statistics. An Introduction using R. West Sussex, UK: Wiley.

Halevy, N., Chou, E., Cohen, T. R., \& Livingston, R. W. (2012). Status conferral in intergroup social dilemmas: behavioral antecedents and consequences of prestige and dominance. Journal of Personality and Social Psychology, 102, 351-366. doi: 10.1037/ a0025515

Hawley, P. H. (2002). Social dominance and prosocial and coercive strategies of resource control in preschoolers. International Journal of Behavioral Development, 26, 167-176. doi: 10.1080/01650250042000726

Hawley, P. H. (2014). The duality of human nature: coercion and prosociality in youths' hierarchy ascension and social success. Current Directions in Psychological Science, 23, 433-438. doi: 10.1177/0963721414548417

Hawley, P. H;Little, T.D., \& Card, N. A. (2008). The myth of the alpha male: a new look at dominance-related beliefs and behaviors among adolescent males and females. International Journal of Behavioral Development, 32, 76-88. doi: 10.1177/0165025407084054

Hawley, P. H.; Little, T. D., \& Pasupathi, M. (2002). Winning friends and influencing peers: strategies 
of peer influence in late childhood. International Journal of Behavioral Development, 5, 466-474. doi: 10.1080/01650250143000427

Henrich, J. \& Gil-White, F. (2001). The evolution of prestige: freely conferred status as a mechanism for enhancing the benefits of cultural transmission. Evolution \& Human Behavior, 22, 1-32. doi: 10.1016/ S1090-5138(00)00071-4

Johnson, R. T., Burk, J. A., \& Kirkpatrick, L. A. (2007). Dominance and prestige as differential predictors of aggression and testosterone levels in men. Evolution \& Human Behavior, 28, 345-351. doi: 10.1016/j.evolhumbehav.2007.04.003

Krützen, M., Mann, J., Heithaus, M. R., Connor, R. C., Bejder, L., \& Sherwin, W. B. (2005). Cultural transmission of tool use in bottlenose dolphins. Proceedings of the National Academy of Sciences of the United States of America, 102, 8939-8943. doi: $10.1073 /$ pnas. 0500232102

Liu, R. X., Kuang, J., Gong, Q., \& Hou, X. L. (2003). Principal components regression analysis with SPSS. Computer Methods and Programs in Biomedicine, 71, 141-147. doi: 10.1016/S0169-2607(02)00058-5

Lodico, M. G., Spaulding, D. T., \& Voegtle, K. H. (2006). Methods in Educational Research: From Theory to Practice. San Francisco, California: Wiley.

Monge-López, D., \& Escorial, S. (2015). Traducción y análisis psicométrico de la Escala de Estatus Social Auto percibido en dos muestras hispanohablantes. Avances en Psicología Latinoamericana, 33, 233-249. doi: 10.12804/apl33.02.2015.05

Reyes-Garcia, V., Molina, J. L., McDade, T. W., Tanner, S. N., Huanca, T., \& Leonard, W. R. (2009). Inequality in social rank and adult nutritional status: Evidence from a small-scale society in the Bolivian Amazon. Social Science \& Medicine, 69, 571-578. doi: 10.1016/j.socscimed.2009.05.039
Sijtsma, K. (2009). On the use, the misuse, and the very limited usefulness of Cronbach's alpha. Psychometrika, 74, 107 - 120. doi: 10.1007/s11336-008-9101-0

Snyder, J. K., Kirkpatrick, L. A., \& Barrett, H. C. (2008). The dominance dilemma: Do women really prefer dominant mates? Personal Relationships, 15, 425-444. doi: 10.1111/j.1475-6811.2008.00208.x

Taylor, M. J., \& Toth, C. A. (2011). Cultural transmission. In Goldstein, S. \& Naglieri, J. A. (Eds.) Encyclopedia of Child Behavior and Development (pp. 448-451) New York: Springer. doi: 10.1007/978-0-387-790619_755

Thompson, E. R. (2008). Development and validation of an international English big-five mini-markers. Personality and Individual Differences, 45, 542-548. doi: 10.1016/j.paid.2008.06.013

Tracy, J. L., Cheng, J. T., Robins, R. W., \& Trzesniewski, K. (2009). Authentic and hubristic pride: the affective core of self-esteem and narcissism. Self and Identity, 8, 196-213. doi: 10.1080/15298860802505053

Tracy, J. L., \& Robins, R. W. (2007). The psychological structure of pride: A tale of two facets. Journal of Personality and Social Psychology, 92, 506-525. doi: 0.1037/0022-3514.92.3.506

Von Rueden, C., Gurven, M., \& Kaplan, H. (2008). The multiple dimensions of male social status in an Amazonian society. Evolution \& Human Behavior, 29, 402-415. doi: 10.1016/j.evolhumbehav.2008.05.001

Von Rueden, C., Gurven, M., \& Kaplan, H. (2011). Why do men seek status? Fitness payoffs to dominance and prestige. Proceedings of the Royal Society B, 278, 2223-2232. doi:10.1098/rspb.2010.2145

Van Schaik, C. P., \& Burkart, J. M. (2011). Social learning and evolution: the cultural intelligence hypothesis. Philosophical Transactions of Royal Society of London Biological Sciences, 366, 1008-1016. doi: 10.1098/rstb.2010.0304

Recibido: 03 de octubre de 2016 Aceptado: 05 de setiembre de 2017 